\title{
Bazı İnstant Gıdaların Üretiminde Kızılötesi Kurutmanın Etkisi
}

\author{
Barış Burak Albayrak ${ }^{1, *}$, Necati Barış Tuncel ${ }^{2}$, Habib Kocabıyık $^{3}$ \\ ${ }^{1}$ Gıda İsleme Bölümü, Pazarlar Meslek Yüksekokulu, Kütahya Dumlupınar Üniversitesi, Kütahya, Türkiye \\ ${ }^{2}$ Gıda Mühendisliği Bölümü, Mühendislik Fakültesi, Çanakkale Onsekiz Mart Üniversitesi, Çanakkale, Türkiye \\ ${ }^{3}$ Tarım Makinaları ve Teknolojileri Mühendisliği Bölümü, Ziraat Fakültesi, Çanakkale Onsekiz Mart Üniversitesi, Çanakkale, Türkiye
}

\begin{abstract}
Makale Tarihçesi
Gönderim: $\quad 21.07 .2020$

Kabul: $\quad 17.09 .2020$

Yayım: $\quad 20.03 .2021$
\end{abstract}

Araştırma Makalesi

\begin{abstract}
Öz - Gıda endüstrisi ve tüketiciler sürekli yeniliğe ve daha kaliteli ürüne ihtiyaç duymaktadır. Yalnızca sıcak su ilavesi ile kolay bir şekilde tüketime hazır hale gelen instant gıdalar, zaman tasarrufu açısından son zamanlarda popülerlik kazanmıştır. İnstant gıdalar, genellikle önce pişirilip daha sonra geleneksel kurutma yöntemi ile kurutularak üretilmektedir. Bu çalışmada, geleneksel kurutma yöntemlerine alternatif olarak kızılötesi teknolojisi kullanılarak fasulye, bulgur, kahverengi ve beyaz pirinçten instant ürün üretilmesi ve fizikokimyasal özelliklerinin araştırılması amaçlanmıştır. Bu amaçla, ürünler pişirilmiş ve farklı güçlerde $(300,400,500 \mathrm{~W})$ orta dalga kızılötesi yayıcı ile kurutulmuștur. Kurutulmus ürünlerde kuruma süresi, su aktivitesi, hidroksimetilfurfural (HMF) miktarı, renk, tekstür ve rehidrasyon yeteneği ölçülerek kızılötesi kurutmanın ürünlere olan etkisi araştırılmıştır. Kızılötesi yayıcı gücünün artmasıyla kuruma sürelerinin beklenen şekilde azaldığı ve kuruma sonrası tüm örneklerin muhafaza açısından güvenli su aktivitelerine (0.29- 0.49) ulaştı̆̆ belirlenmiştir. Uygulanan işlemler sonucu kahverengi ve beyaz pirinçte HMF oluşumu görülmemekle birlikte bulgur ve fasulye örnekleri için HMF olușumunda kuruma süresinin etkili olduğu saptanmıştır $(\mathrm{p}<0.05)$. Bununla birlikte yüksek rehidrasyon yetenekleri sergileyen örneklerin sertlik değerlerinin daha az olduğu gözlenmiştir. Ayrıca, bulgur ve fasulye örneklerinin rehidrasyon yetenekleri kızı̈ötesi yayıcı güçlerinden etkilenmemiştir ( $p>0.05$ ). Sonuç olarak, piyasadaki instant gıda yelpazesine yeni ürünler ekleme ve instant gıda üretiminde kızılötesi kurutmanın kullanılabilme potansiyeli ortaya konmuştur.
\end{abstract}

Anahtar Kelimeler - hidroksimetilfurfural (HMF), instant, kızllötesi, rehidrasyon, tekstür

\section{The Effect of Infrared Drying in the Production of Some Instant Foods}

\author{
${ }^{1}$ Department of Food Processing, Pazarlar Vocational School, Kütahya Dumlupınar University, Kütahya, Turkey \\ ${ }^{2}$ Department of Food Engineering, Faculty of Engineering, Çanakkale Onsekiz Mart University, Çanakkale, Turkey \\ ${ }^{3}$ Department of Agricultural Machinery and Technologies Engineering, Faculty of Agriculture, Çanakkale Onsekiz Mart University, \\ Çanakkale, Turkey
}

\section{Article History \\ Received: $\quad 21.07 .2020$ \\ Accepted: $\quad 17.09 .2020$ \\ Published: $\quad 20.03 .2021$}

Research Article

\begin{abstract}
The food industry and consumers need constant innovation and higher quality products. Instant foods, which are ready to consume only with addition of hot water, have recently gained popularity from the standpoint of time saving. Generally, instant foods are manufactured by cooking and drying with a conventional method, sequentially. In this study, it was aimed to produce instant products by using infrared technology, which is an alternative to conventional drying methods, from beans, bulgur, brown and white rice and to investigate physicochemical of properties. For this purpose, the noted materials were cooked and dried with medium-wave infrared emitters at the power of 300, 400, and $500 \mathrm{~W}$. The effect of infrared drying on drying time, water activity, hydroxymethylfurfural (HMF), color, texture and rehydration ability of the products were investigated. It was determined that drying time decreased with the increase of infrared power, as expected and the water activity of the products decreased to safe levels (0.29-0.49). Although HMF was not formed in brown and white rice, it was determined in bulgur and bean and drying time was effective in HMF levels found in bulgur and bean ( $<<0.05$ ). Additionally, it was observed that hardness levels of samples which exhibited higher rehydration abilities were lower. Moreover, rehydration ability of bulgur and bean samples was not affected by the power of infrared emitter ( $>0.05$ ). In conclusion, the potential of adding new products to the instant food category in the market and using infrared drying in instant food production have been demonstrated.
\end{abstract}

Keywords - Hydroxymethylfurfural (HMF), instant, Infrared, rehydration, texture

\footnotetext{
1 (D) baris.albayrak@dpu.edu.tr

2 (1D) baristuncel@ comu.edu.tr

3 (D) kocabiyikh@comu.edu.tr

*Sorumlu Yazar / Corresponding Author
} 


\section{Giriş}

İnsanların varoluşundan bu yana gelişen ekipmanlar ve imkanlar doğrultusunda yemek alışkanlıkları değişmiş ve gelişmiştir (Ramasamy, Kalaivanan ve Sukumar, 2005). Ayrıca, günümüzde dünya nüfusunun artışı ve buna karşılık kaynakların sınırlı olmasıyla birlikte insanlar gıda tüketiminde zaman tasarrufuna da yönelmiştir. Bu nedenlerden dolayı, instant gıdalar dünya çapında popülerlik kazanmıştır. Örneğin, sadece sıcak su ilavesi ile tüketilebilir forma dönüşen instant gidalar grubunda bulunan, erişte (noodle) ürünlerinin 2018 y1lı verilerine göre, 42.2 milyar ABD Doları değerinde bir pazar payına sahip olduğu ve 2024 y1lına kadar pazar payının 57.5 milyar ABD Dolarına ulaşacağı tahmin edilmektedir (Research And Markets, 2019). Bu talepler doğrultusunda instant ürün yelpazesine yeni gıdaların eklenebilmesi için Ar-Ge çalışmalarına ihtiyaç duyulmaktadır.

İnstant gıda üretimi kısaca; önce pişirme daha sonra uygun kurutma yöntemi ile kurutmaya dayanmaktadır (Sripinyowanich ve Noomhorm, 2013). İnstant gıdanın kalitesi, ham maddeye ve kurutma koşullarına bağlıdır. Bununla birlikte kurutma işlemi, instant gıda hazırlanmasında en kritik adım olarak kabul edilmektedir (Ramesh ve Rao, 1996). Diğer yandan sadece sicak suyla tüketilebilir forma gelen instant gida için aranan en önemli parametre ise rehidrasyon yeteneğidir ve instant gidaya sicak suyun verilmesinin ardından pişmiş haline geri dönüşebilme oranını ifade etmektedir (İsmail, 2017).

Kurutma yöntemi ve koşullarına bağlı olarak değişen yapı (büzüşme, hücre yapılarının bozulması vb.) kurutulmuş ürünlerin rehidrasyon yeteneğini olumsuz etkilemektedir (Cemeroğlu, Karadeniz ve Özkan, 2003). Yapılan çalışmalarda, instant pirincin kurutulmasında farklı kurutma yöntemleri kullanılmıştır. Özellikle sıcak hava ile kurutma, gıdaları korumak için kullanılan eski bir prosestir ve instant pirinç

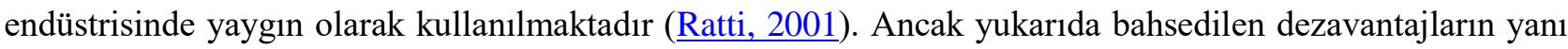
sıra kuruma süresi uzun ve enerji verimliliği düşüktür (Mayor ve Sereno, 2004). Bu kısıtlamalar, instant gıda üretiminde kızılötesi (IR) enerji ile kurutma gibi yeni teknolojilerin kullanım olanaklarının araştırılmasına yol açmıştır.

Kızı̈ötesi (IR), 1sıl enerjiyi elektromanyetik dalga olarak ileten ve elektromanyetik spektrumda mikrodalga ile görünür 1şık bölgelerinin arasında bulunan bir ışınım türüdür. Aynı zamanda güneşin 1sıtma etkisinden de IR enerji büyük oranda sorumludur (Jun vd., 2010). IR yoluyla termal enerji, çevredeki havayı 1sitmadan direkt olarak ürüne aktarılmakta ve dolayısıyla daha hızlı bir 1sı transferi sağlanmaktadır (Das ve Das, 2010; Nowak ve Lewicki, 2004). Mongpreneet, Abe ve Tsurusaki (2002) ve Chua ve Chuo (2003), IR enerji ile kurutmanın geleneksel yöntemlere (sıcak hava ile kurutma) kıyasla; hızlı, basit, ekonomik ve yüksek kaliteli son ürün üretimi gibi pek çok avantaja sahip olduğunu belirtmişlerdir. Bununla birlikte IR enerji diğer kullanım alanlarındaki tekniklere (kızartma, kavurma, 1sıtma, çözdürme ve enzim inaktivasyonu) göre en çok kurutma tekniği olarak kullanılmaktadır (Tuncel ve Tuncel 2016; Krishnamurthy, 2008; Nowak ve Lewicki, 2004).

Jiao, Xu ve Jin (2014), mikrodalga enerjisini, geleneksel sıcak hava yöntemini ve kombinasyonlarını instant beyaz pirinç üretiminde, Le ve Jittanit (2015) ise instant kahverengi pirinç üretiminde kurutma aşamasında kullanmışlardır. Literatür incelendiğinde kuru fasulye ve bulgur kullanılarak yapılan instant gıda üretimine yönelik bir çalışmaya rastlanmamıştır. Bununla birlikte instant kahverengi ve beyaz pirinç hakkında bilimsel çalışmalar olsa da kurutmada IR enerjinin kullanıldığı bir çalışmaya ulaşılamamıştır.

Gıdalarda uygulanan 1sıl işlemler sonucu, insan sağlığına zararlı bir bileşik olarak kabul edilen ve Maillard reaksiyonunun bir ara ürünü olan 5-hidroksimetilfurfural (HMF)'1n oluştuğu birçok araştırmacı tarafından rapor edilmiştir. Aynı zamanda bu reaksiyon sonucu gıdalarda aminoasit ve şeker miktarlarında azalma meydana geldiğinden, HMF miktarının belirlenmesi bir kalite göstergesi olarak kabul edilmektedir (Kayacan vd., 2020; Güray vd., 2019). Karbonhidrat ve protein bakımından zengin olan instant gıdalara, üretimi 
esnasında uygulanan 1sıl işlemlerin HMF oluşumunu tetikleyebileceği düşünülmüsstür. Bu nedenle ürünlerin HMF miktarlarının belirlenmesi gerekliliği ortaya çıkmıştır. Bu çalışmada, kuru fasulye, bulgur, kahverengi ve beyaz pirinç pilavından instant ürün üretiminde kızılötesi kurutma teknolojisinin kullanılma potansiyeli ve kurutmanın ürün kalitesine ve bazı özelliklere etkisi incelenmesi amaçlanmıştır.

\section{Materyal ve Yöntem}

\subsection{Materyal}

Materyal olarak kullanılan kuru fasulye (Sıra), kahverengi pirinç (Osmancık), pilavlık bulgur ve pirinç (baldo) piyasadan temin edilmiştir.

\subsection{Yöntem}

\subsubsection{Hazırlık ve IR Kurutma İşlemi}

Yalnızca kuru fasulye örneklerinde oda sıcaklığında $\left(25^{\circ} \mathrm{C}\right)$, 18 saat ön ıslatma işlemi uygulanmıştır. Ardından materyaller yıkanarak pişirme (haşlama) işlemine tabi tutulmuştur. Atmosfer basıncında uygulanan bu aşamada kuru fasulye, kahverengi pirinç, bulgur ve beyaz pirinç örneklerinde kaynatma işlemi sırasıyla 50, 45, 20 ve 8 dakika boyunca gerçekleştirilmiştir. Pişmiş ürünlerde tanelerin birbirine yapışması sorununun giderilmesi ve pişme nemlerinin standardizasyonunu sağlamak amacıyla örnekler $25{ }^{\circ} \mathrm{C}$ su banyosunda 2 dakika bekletilmiştir. Bu işlemlerden sonra yüzey nemlerini uzaklaştırmak amacıyla örnekler süzülmüştür. Hazırlık aşamasındaki süre parametreleri ön denemeler neticesinde belirlenmiştir.

Kurutma işlemi 70 x 40 x $50 \mathrm{~cm}$ boyutlarında paslanmaz çelik saçtan oluşan kurutma kabini içerisinde 1250 W gücündeki altın reflektörlü orta dalga kızılötesi (IR) yayıcı (Heraeus Noblelight, Hanau, Almanya) ile gerçekleştirilmiştir. IR enerji kaynağı ile ürün yüzeyi arasındaki mesafe ve hava hızı tüm kurutma işlemlerinde sirasıyla $20 \mathrm{~cm}$ ve $1 \mathrm{~m} / \mathrm{s}$ olacak şekilde sabit tutulmuştur. Ürünler 30 x $40 \mathrm{~cm}$ boyutlarındaki teflon kaplı tel örgü biçimindeki kurutma tepsisi üzerine 15 x $30 \mathrm{~cm}$ 'lik alana serilmiştir. Deneyler boyunca her bir ürün için $300 \mathrm{~W}, 400 \mathrm{~W}$ ve $500 \mathrm{~W}$ gücünde IR enerji ile kurutma işlemleri gerçekleştirilmiştir (Kocabiyik vd., 2014).

Kuruma sürelerini tespit etmek amacıyla kuruma eğrilerini izlemek için bilgisayar ile bağlantısı yapılmış \pm 0.01 g hassasiyete sahip dijital terazi (Precisa XB 3200C, Zürih, İsviçre) kullanılmıştır. Bu işlem için Balint Interface yazılımının (Precisa Instruments AG, Zürih, İsviçre) yardımıyla 3 dakika aralıklarla örneklerin ağırlık (su) kayıpları kaydedilmiştir.

\subsubsection{Nem Tayini}

Pişmiş ve kuru ürünlerin nem içeriği gravimetrik olarak AACC standartlarında (44-15A) yer alan yönteme göre belirlenmiş̧ir (AACC, 2000).

\subsubsection{Su Aktivitesi $\left(a_{w}\right)$ Analizi}

Ögütülüp 212 mikron elekte elek altına geçen örnekler numune kabına $2.00 \pm 0.05 \mathrm{~g}$ tartılarak Aqua Lab - 4 TE model su aktivitesi cihazında (Decagon Devices, Pullman, ABD) analize tabi tutulmuştur. Ölçüm sıcaklı̆̆ $125^{\circ} \mathrm{C}$ olmak üzere su aktivitesi değerleri iki tekerrürlü olarak elde edilmiştir.

\subsubsection{Rehidrasyon Yeteneği}

Rehidrasyon yeteneği analizi Jiao vd. (2014)'nin kullandıkları yöntem modifiye edilerek uygulanmıştır. IR enerji ile kurutulmuş ürünlerin rehidrasyon yeteneğini belirlemek için 5 ayrı behere $4.0 \pm$ 
$0.1 \mathrm{~g}$ numune tartılarak üzerine $85^{\circ} \mathrm{C}$ sıcaklığında $40 \mathrm{~mL}$ saf su eklenmiştir. Ardından $85^{\circ} \mathrm{C}$ su banyosunda rehidre edilen ürünler $3 \mathrm{dk}$ aralıklarla alınarak süzülüp hassas terazide tartılmıştır. Böylelikle instant ürünlerin süreç boyunca bünyelerine aldıkları nem miktarı (kuru madde bazında) gravimetrik olarak hesaplanmıştır. Elde edilen sonuçlarla birlikte, 3., 6., 9., 12. ve 15. dakikalardaki rehidrasyon yetenekleri (RY, \%), kurutmadan önceki pişmiş ürünlerin ilk nem miktarları da dikkate alınarak, aşağıdaki denklem 2.1 ile hesaplanmıştır. Analiz iki tekerrürlü olacak şekilde gerçekleştirilmiş̧ir.

$\mathrm{RY}=\frac{M r}{M p} \times 100$

RY : Rehidrasyon yeteneği (\%)

$\mathrm{Mr} \quad$ : Rehidre edilen örneklerin nem içeriği (g / g KM)

Mp : Kurutmadan önceki pişmiş ürünlerin nem içeriği (g / g KM)

\subsubsection{Renk Analizi}

Pişirilmemiş kontrol örnekleri (k) ve IR enerji ile kurutulmuş ürünler (i) ögütüldükten sonra 212 mikron elekte elenmiş ve renk analizleri Minolta Cr-220 cihazı (Minolta Co., Osaka, Japonya) kullanılarak gerçekleştirilmiştir. CIE Lab renk uzayında ölçülen L (parlaklık), a (kırmızı-yeşil) ve b (sarı-mavi) değerlerinden yararlanılarak toplam renk değişimi $(\Delta \mathrm{E})$ aşağıdaki denklem $\underline{2.2}$ ile hesaplanmıştır. Numuneler 4 tekerrürlü olacak şekilde ölçülmüş̧ür.

$\Delta \mathrm{E}=\sqrt{\left(L_{i}-L_{k}\right)^{2}+\left(a_{i}-a_{k}\right)^{2}+\left(b_{i}-b_{k}\right)^{2}}$

\subsubsection{Rehidrasyon Sonrası Tekstürel Analiz}

İnstant gidaların rehidre edilerek tüketileceği göz önünde bulundurulduğunda, tekstürel analizin rehidrasyon sonrası yapılmasına karar verilmiştir. Bunun için duyusal açıdan tüketilebilir forma gelebildiği ilk rehidrasyon süresinin temel alınması hedeflenmiştir. Çalışma süresince yapılan ön denemelerde elde edilen tekstür sonuçlarının yeterli tekrar edilebilirliği rehidrasyon uygulamasının 9. dakikasında belirlenmiştir. 15. dakikada örnekler dağılmış, 6. dakikadan kısa sürede de tüketilemez düzeyde sert ürün elde edilmiştir. Görsel açıdan incelendiğinde de 9 dakikalık rehidrasyon süresinin yeterli olduğu görülmektedir (bkz. Şekil $\underline{1}$ ).

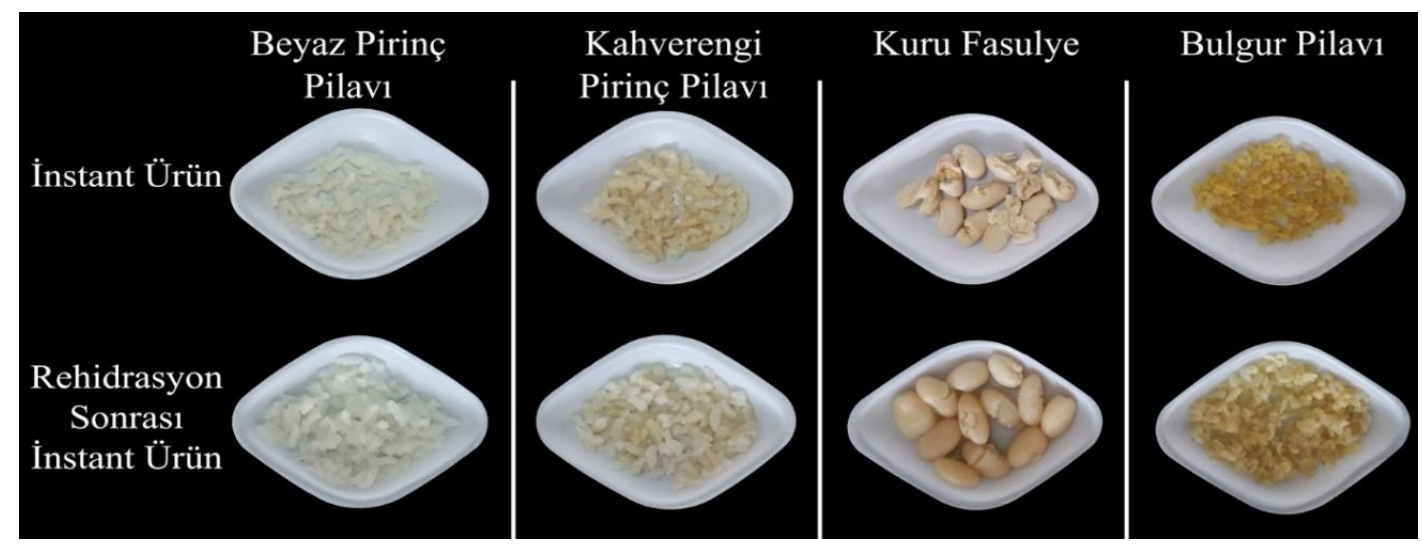

Şekil 1. 400 W IR yayıcı gücünde kurutulan örneklerin rehidrasyon öncesi ve sonrası durumları (9. dakika) 
Tekstür profil analizi için IR yayıcı ile kurutulmuş ürünlerin her birinden beher içerisine $10 \mathrm{~g}$ örnek alınarak rehidrasyon yönteminde (bkz. Başlık 2.2.4.) de belirtildiği gibi üzerine $85{ }^{\circ} \mathrm{C}$ sicaklığında $40 \mathrm{~mL}$ saf su eklenmiştir. Ardından beherler $85{ }^{\circ} \mathrm{C}$ su banyosunda $9 \mathrm{dk}$ boyunca rehidre edilmiştir. Rehidrasyonu tamamlanan ürünler Brookfield marka CT3-4500 model tekstür analiz cihazında (Massachusetts, ABD) analiz edilmiştir. Ottawa cell (TA-OC) tabla düzeneğinde, tekstür probu (TA3/100) kullanılarak, $50 \mathrm{~g}$ bask1 ile Tekstür Profil Analizleri (TPA) gerçekleştirilmiştir. Sıkıştırma işlemi sonucunda ürünlerin, sertlik (g), dış yapışkanlık (mJ), elastikiyet, bağlılık, esneklik (mm), sakızlılık (g) ve çiğnenebilirlik (mJ) özellikleri tespit edilmiştir. Tekstür analizi iki tekerrürlü olarak gerçekleştirilmiştir.

\subsubsection{HMF Analizi}

Hidroksimetilfurfural (HMF) analizi Güray vd. (2019) kullandıkları yöntem kısmen modifiye edilerek uygulanmıştır. Öğütülmüş ürünler santrifüj tüplerine $1 \mathrm{~g}$ (kuru ağırlık) tartılmış, üzerine $10 \mathrm{~mL}$ deiyonize su eklenerek $2 \mathrm{dk}$ vorteks uygulanmış, sonrasında oda sıcaklığında çalkalayıcı yardımıyla 200 rpm'de 10 dk çalkalanmıştır. Ardından 5 dk 9000 rpm santrifüj uygulandıktan sonra kaba filtre kağıdından geçirilerek alüminyum folyo ile kaplanmış santrifüj tüplerine dökelti toplanmıştır. Santrifüj tüplerine $250 \mu \mathrm{L}$ Carrez I ve $250 \mu \mathrm{L}$ Carrez II eklenerek 2 dk vortex edilmiş ve tekrar 200 rpm'de 10 dk çalkalanmıştır. Ardından $5{ }^{\circ} \mathrm{C}$ 'de $10 \mathrm{dk}$ santrifüj $(9000 \mathrm{rpm})$ uygulanmıştır. İşlem sonunda dökelti $45 \mu \mathrm{m}$ filtreden geçirilerek amber renkli viallere alınarak HPLC'de analiz edilmiştir. Kromatografik analiz Agilent Zorbax C18 kolonu ( 250 x $4.6 \mathrm{~mm} 5 \mu \mathrm{m})$ kullanılarak isokratik akışta \% 0.1'lik formik asitli su ve asetonitril (7:93) mobil fazında, akış hızı $1 \mathrm{~mL} / \mathrm{dk}$ olacak şekilde ve $30^{\circ} \mathrm{C}$ kolon sıcaklığında gerçekleştirilmiştir. Enjeksiyon hacmi $20 \mu \mathrm{L}$ olup ve $285 \mathrm{~nm}$ dalga boyunda 2 tekerrür ve 2 paralelli olacak şekilde uygulanan analiz işleminin sonuçları HMF kalibrasyon eğrisi yardımıyla "mg / 100 g (KM)" olarak hesaplanmıştır. Kullanılan kimyasallar Sigma-Aldrich (St. Louis, ABD)'den temin edilmiştir.

\subsection{8. İstatistiksel Analizler}

Verilerin istatistiksel değerlendirilmesinde MINITAB 17v (StatSoft Inc., Tulsa, OK., ABD) yazılımı kullanılmıştır. Kurutma işlemi koşullarının (IR yayıcı güçlerinin) bulgur, fasulye, kahverengi ve beyaz pirinç numuneleri için incelenen özelliklerine etkisi tek yönlü varyans analizi (ANOVA) ile Tukey testine göre incelenmiştir $(\mathrm{p}<0.05)$. Analiz sonuçları "ortalama \pm standart hata" olarak ifade edilmiştir.

\section{Bulgular ve Tartışma}

İnstant bulgur, fasulye, kahverengi ve beyaz pirinç örneklerinin üretimi esnasında uygulanan IR yayıcı güçleri, kuruma süreleri, son nem içerikleri, su aktivitesi değerleri ve HMF miktarları Tablo 1 'de verilmiştir. 
Tablo 1

Farklı IR yayıcı güçlerinde üretilen instant ürünlerin bazı fizikokimyasal özellikleri

\begin{tabular}{|c|c|c|c|c|c|}
\hline $\begin{array}{l}\text { İnstant } \\
\text { Ürün }\end{array}$ & $\begin{array}{l}\text { IR Gücü } \\
(W)\end{array}$ & $\begin{array}{l}\text { Kuruma } \\
\text { Süresi (dk) }\end{array}$ & Son $\operatorname{Nem}(\%)$ & $\mathbf{a}_{\mathbf{w}}$ & $\begin{array}{l}\text { HMF } \\
(\mathrm{mg} / 100 \mathrm{~g})\end{array}$ \\
\hline \multirow[t]{4}{*}{ Bulgur } & 300 & $102.0 \pm 0.1^{\mathrm{A}}$ & $7.09 \pm 0.02^{\mathrm{A}}$ & $0.41 \pm 0.01$ & $0.107 \pm 0.002^{\mathrm{A}}$ \\
\hline & 400 & $79.5 \pm 1.5^{\text {в }}$ & $7.38 \pm 0.09^{\mathrm{A}}$ & $0.41 \pm 0.01$ & $0.050 \pm 0.001^{\mathrm{B}}$ \\
\hline & 500 & $61.5 \pm 1.5^{\mathrm{C}}$ & $6.32 \pm 0.09^{\mathrm{B}}$ & $0.40 \pm 0.01$ & $0.048 \pm 0.001^{\mathrm{B}}$ \\
\hline & & $p=0.000$ & $\mathrm{p}=0.005$ & & $\mathrm{p}=0.000$ \\
\hline \multirow[t]{4}{*}{ Fasulye } & 300 & $117.0 \pm 6.0^{\mathrm{A}}$ & $6.99 \pm 0.26^{\mathrm{A}}$ & $0.42 \pm 0.01$ & $0.163 \pm 0.004^{\mathrm{B}}$ \\
\hline & 400 & $97.5 \pm 1.5^{\mathrm{AB}}$ & $5.79 \pm 0.01^{\mathrm{B}}$ & $0.37 \pm 0.01$ & $0.205 \pm 0.003^{\mathrm{A}}$ \\
\hline & 500 & $84.0 \pm 3.0^{\mathrm{B}}$ & $4.64 \pm 0.07^{\mathrm{C}}$ & $0.33 \pm 0.01$ & $0.146 \pm 0.001^{\mathrm{B}}$ \\
\hline & & $p=0.022$ & $\mathrm{p}=0.004$ & & $\mathrm{p}=0.002$ \\
\hline \multirow{4}{*}{$\begin{array}{l}\text { Kahverengi } \\
\text { Pirinç }\end{array}$} & 300 & $78.0 \pm 0.1^{\mathrm{A}}$ & $8.00 \pm 0.07^{\mathrm{B}}$ & $0.44 \pm 0.01$ & T.E. \\
\hline & 400 & $70.5 \pm 1.5^{\mathrm{B}}$ & $10.52 \pm 0.09^{\mathrm{A}}$ & $0.49 \pm 0.01$ & T.E. \\
\hline & 500 & $61.5 \pm 1.5^{\mathrm{C}}$ & $10.36 \pm 0.07^{\mathrm{A}}$ & $0.49 \pm 0.01$ & T.E. \\
\hline & & $p=0.006$ & $\mathrm{p}=0.000$ & & \\
\hline \multirow[t]{4}{*}{ Pirinç } & 300 & $99.0 \pm 0.1^{\mathrm{A}}$ & $7.82 \pm 0.04^{\mathrm{A}}$ & $0.37 \pm 0.01$ & T.E. \\
\hline & 400 & $91.5 \pm 1.5^{\mathrm{B}}$ & $7.87 \pm 0.02^{\mathrm{A}}$ & $0.38 \pm 0.01$ & T.E. \\
\hline & 500 & $84.0 \pm 0.1^{\mathrm{C}}$ & $5.80 \pm 0.14^{\mathrm{B}}$ & $0.29 \pm 0.01$ & T.E. \\
\hline & & $\mathrm{p}=0.003$ & $\mathrm{p}=0.001$ & & \\
\hline
\end{tabular}

A-C Her bir ürün satırı özelinde, aynı sütunda farklı büyük harflerle gösterilen ortalamalar birbirinden farklıdır ( $\mathrm{p}<0.05)$. (T.E.: tespit edilmedi)

Ürünlerin son nem içerikleri yaklaşık \%7 - 8 olacak şekilde kurutma işlemi uygulanmıştır. Ancak kuruma sonrasında yapılan gravimetrik nem tayini sonuçlarında farklılıklar belirlenmiştir. Bulgur, fasulye, kahverengi pirinç ve pirinç için sırasıyla \%6.32 - 7.38, \%4.64 - 6.99, \%8.00 - 10.52, \%5.80 - 7.82 aralığındaki değişkenliğin sebebinin ortam koşullarının sıcaklık ve nem düzeyinin, işlem sonrasında nem kaybına/kazanımına neden olması gösterilebilir. Diğer yandan kurutma kabini altında bulunan terazi ile ağırlık kaybına bağlı rutubet değeri hesaplayan yazılımın verdiği değerler ile gravimetrik sonuçlar arasında farklılıklar olabilmektedir. Su aktivitesi $\left(\mathrm{a}_{\mathrm{w}}\right)$ değerleri ise genel olarak $0.29-0.49$ aralığında belirlenmiş olup her bir ürün için ayrı ayrı incelendiğinde son nem içerikleri ile doğrusal bir ilişki bulunmuştur ( $\mathrm{p}<$ 0.05). Ayrıca, $a_{w}<0.60$ olan düşük nemli gıdalarda genel olarak mikrobiyel faaliyetlerin durduğu bilinmektedir (Erkmen ve Bozoglu, 2016). Nitekim instant ürünlerin muhafazası için kuruma sonrası güvenli $a_{w}$ değerlerine ulaşıldığı söylenebilir. 
IR yayıcı gücünün artmasıyla kuruma sürelerinin beklenen şekilde azaldığı, bu durumun istatistiksel sonuçlara yansıdığı tespit edilmiştir $(\mathrm{p}<0.05)$. IR yayıcı gücünün artması ile $\mathrm{cm}^{2}$ başına düşen radyasyon yoğunluğunun artması kuruma sürelerinin kısalmasının ana sebebidir. Nitekim bu durum, bulgur (Savas ve Basman, 2016), instant çimlenmiş kahverengi pirinç (Nachaisin, Jamradloedluk ve Niamnuy, 2016), instant erişte (noodle) (Basman ve Yalcin, 2011) ve soya fasulyesi (Wiriyaumpaiwong, Soponronnarit ve Prachayawarakorn, 2004) gibi hububat ürünleri ile yapılan çalışmalarda rapor edilen sonuçlarla benzerlik göstermektedir.

İnstant ürünler incelendiğinde bulgur ve fasulye örneklerinde HMF tespit edilmiş ancak kahverengi ve beyaz pirinçte belirlenememiştir. Pirinç grubundaki örneklerin tespit edilememesinin nedeni diğer örneklere göre protein ve indirgen şeker miktarının az olmasından kaynaklandığı düşünülmektedir. (Rufian-Henares, Delgado-Andrade ve Morales, 2009). Fasulye örneklerinde, uzun kuruma sürelerinde düşük IR gücünün, yüksek IR gücünde de kısa kuruma süresinin HMF oluşumuna olumsuz etkide bulunduğu söylenebilir ( $\mathrm{p}<$ 0.05). Ara değer olan $400 \mathrm{~W}$ IR gücünde yapılan kurutma işleminde ise HMF değerinin az da olsa yüksek çıkması, kuruma süresinin 500 W'a maruz kalmış örneğe göre biraz daha fazla olmasına aynı zamanda IR gücünün $300 \mathrm{~W}$ 'a göre daha yüksek olmasına bağlanmıştır. Bulgur örneklerinde kuruma süresi dolayısıyla da IR enerjiye maruz kalma süresi arttıkça HMF miktarının arttığı belirlenmiştir $(\mathrm{p}<0.05)$. Böylelikle bulgur örneklerinde HMF oluşumunda IR gücüne kıyasla kuruma süresinin daha çok etkili olduğu söylenebilir. Nitekim, Kayacan vd. (2020), hurmanın kurutulmasında farklı kurutma yöntemlerini karşılaştırdıkları bir çalışmada, ssıya maruz kalma süresinin HMF oluşumunun ana nedeni olabileceğini rapor etmişlerdir. Sonuç olarak 500 W IR gücünün kullanılması üründe hızlı kurumanın yanı sıra HMF oluşumunu da azaltması bir avantaj olarak düşünülebilir.

İnstant ürünlerin CIE Lab renk uzayında ölçülen değerleri ve kuruma işlemi ile meydana gelen toplam renk değişimleri Tablo $\underline{2}$ 'de verilmiştir. Tüm instant ürünler için $\mathrm{L}$, a ve $\mathrm{b}$ değerlerinin pişirilmemiş kontrol örneklerinden farklı olduğu istatistiksel olarak önemli bulunmuştur $(\mathrm{p}<0.05)$. Bu fark toplam renk değişimi $(\Delta \mathrm{E})$ olarak ifade edildiğinde IR güçleri arasında bulgur ve pirinç için farkın önemli olmadığı ( $\mathrm{p}>0.05)$, fasulye ve kahverengi pirinç için ise farkın önemli olduğu tespit edilmiştir $(\mathrm{p}<0.05)$. 
Tablo 2

Farklı IR güçlerinde üretilen instant ürünlerin, CIE Lab renk uzayında ölçülen L (parlaklık), a (kırmızıyeşil), b (sarı-mavi) ve $\Delta \mathrm{E}$ (toplam renk değişimi) değerleri

\begin{tabular}{llllll}
\hline & $\begin{array}{l}\text { IR Gücü } \\
(\mathbf{W})\end{array}$ & $\mathbf{L}$ & $\mathbf{a}$ & $\mathbf{b}$ & $\begin{array}{l}\text { Toplam Renk } \\
\text { Değişimi }(\boldsymbol{\Delta} \mathbf{E})\end{array}$ \\
\hline Bulgur & $\mathrm{K}$ & $87.3 \pm 0.2^{\mathbf{A}}$ & $-2.86 \pm 0.04^{\mathbf{B}}$ & $25.2 \pm 0.2^{\mathbf{B}}$ & - \\
& 300 & $85.5 \pm 0.1^{\mathbf{B}}$ & $-2.57 \pm 0.02^{\mathbf{A}}$ & $27.2 \pm 0.3^{\mathbf{A B}}$ & $2.71 \pm 0.21$ \\
& 400 & $86.1 \pm 0.3^{\mathbf{B}}$ & $-3.03 \pm 0.09^{\mathbf{B}}$ & $28.4 \pm 0.9^{\mathbf{A}}$ & $3.45 \pm 0.95$ \\
& 500 & $85.4 \pm 0.3^{\mathbf{B}}$ & $-2.90 \pm 1.08^{\mathbf{B}}$ & $28.4 \pm 0.5^{\mathbf{A}}$ & $3.67 \pm 0.57$ \\
& & $p=0.000$ & $p=0.002$ & $p=0.005$ & $p=0.567$ \\
\hline Fasulye & $\mathrm{K}$ & $92.0 \pm 0.1^{\mathbf{A}}$ & $-0.10 \pm 0.04^{\mathbf{A}}$ & $10.0 \pm 0.3^{\mathbf{C}}$ & - \\
& 300 & $90.2 \pm 0.1^{\mathbf{C}}$ & $-0.08 \pm 0.02^{\mathbf{A}}$ & $13.2 \pm 0.1^{\mathbf{A}}$ & $3.69 \pm 0.08^{\mathbf{A}}$ \\
& 400 & $90.6 \pm 0.1^{\mathbf{B}}$ & $-0.26 \pm 0.02^{\mathbf{B}}$ & $12.7 \pm 0.1^{\mathbf{A}}$ & $3.06 \pm 0.04^{\mathbf{B}}$ \\
& 500 & $91.6 \pm 0.1^{\mathbf{A}}$ & $-0.17 \pm 0.02^{\mathbf{A B}}$ & $11.5 \pm 0.1^{\mathbf{B}}$ & $1.65 \pm 0.12^{\mathbf{C}}$ \\
& & $p=0.000$ & $p=0.003$ & $p=0.000$ & $p=0.000$ \\
\hline Kahverengi & $\mathrm{K}$ & $85.4 \pm 0.3^{\mathbf{C}}$ & $-2.90 \pm 0.08^{\mathbf{B}}$ & $28.4 \pm 0.5^{\mathbf{A}}$ & - \\
Pirinç & 300 & $87.2 \pm 0.1^{\mathbf{B}}$ & $-0.19 \pm 0.11^{\mathbf{A}}$ & $13.1 \pm 0.1^{\mathbf{B}}$ & $1.48 \pm 0.11^{\mathbf{A}}$ \\
& 400 & $87.3 \pm 0.3^{\mathbf{B}}$ & $-0.04 \pm 0.01^{\mathbf{A}}$ & $13.2 \pm 0.2^{\mathbf{B}}$ & $1.46 \pm 0.15^{\mathbf{A}}$ \\
& 500 & $88.2 \pm 0.1^{\mathbf{A}}$ & $-0.17 \pm 0.03^{\mathbf{A}}$ & $12.5 \pm 0.1^{\mathbf{B}}$ & $0.71 \pm 0.05^{\mathbf{B}}$ \\
& & $p=0.000$ & $p=0.000$ & $p=0.000$ & $p=0.001$ \\
\hline Pirinç & $\mathrm{K}$ & $94.1 \pm 0.1^{\mathrm{A}}$ & $-0.43 \pm 0.02^{\mathbf{A}}$ & $6.4 \pm 0.1^{\mathbf{C}}$ & - \\
& 300 & $92.6 \pm 0.3^{\mathbf{B}}$ & $-1.29 \pm 0.03^{\mathbf{B C}}$ & $9.0 \pm 0.2^{\mathbf{A B}}$ & $3.16 \pm 0.3$ \\
& 400 & $92.4 \pm 0.1^{\mathbf{B}}$ & $-1.21 \pm 0.02^{\mathbf{B}}$ & $8.4 \pm 0.2^{\mathbf{B}}$ & $2.77 \pm 0.1$ \\
& 500 & $92.5 \pm 0.2^{\mathrm{B}}$ & $-1.37 \pm 0.01^{\mathbf{C}}$ & $9.5 \pm 0.2^{\mathbf{A}}$ & $3.62 \pm 0.3$ \\
& & $p=0.000$ & $p=0.000$ & $p=0.000$ & $p=0.104$
\end{tabular}

A-C Her bir ürün satırı özelinde, aynı sütunda farklı büyük harflerle gösterilen ortalamalar birbirinden farklidır $(\mathrm{p}<0.05)$.

Fasulye ve kahverengi pirinçte IR gücünün yüksek olduğu durumlarda renk değişiminin en az olduğu görülmekle beraber IR enerjiye maruz kalma süresinin toplam renk değişimi $(\Delta \mathrm{E})$ üzerine daha etkin olduğu tespit edilmiştir. Benzer şekilde, Le ve Jannit (2015), mikrodalga ile kurutma yönteminde uzun kurutma süresi uygulandıkça numunelerde parlaklığın azaldığını ifade etmişlerdir. Sonuçlar genel olarak değerlendirildiğinde, yapılan işlemin renk değerlerinde istatistiksel açıdan önemli değişikliklere neden olduğu, ancak bu değişimin pratikte önemli olmadığı sonucu ortaya çıkmıştır.

Şekil 2 incelendiğinde bulgur ve fasulye örneklerinin rehidrasyon yeteneklerinin farklı IR yayıcı güçlerinden etkilenmediği görülmektedir ( $p>0.05$ ). Düşük IR yayıc1 gücünde $(300 \mathrm{~W}$ ) kurutulan kahverengi pirinçlerin rehidrasyon yetenekleri (özellikle 12. dakikadan sonra), diğer IR yayıcı güçlerine kıyasla daha yüksek değerler kaydetmiştir $(\mathrm{p}<0.05)$. Buna karşın, pirinç örneklerinin en yüksek rehidrasyon yeteneği (özellikle 9. dakikadan sonra) yüksek IR yayıcı gücünde $(500 \mathrm{~W})$ tespit edilmiştir $(\mathrm{p}<0.05)$. 


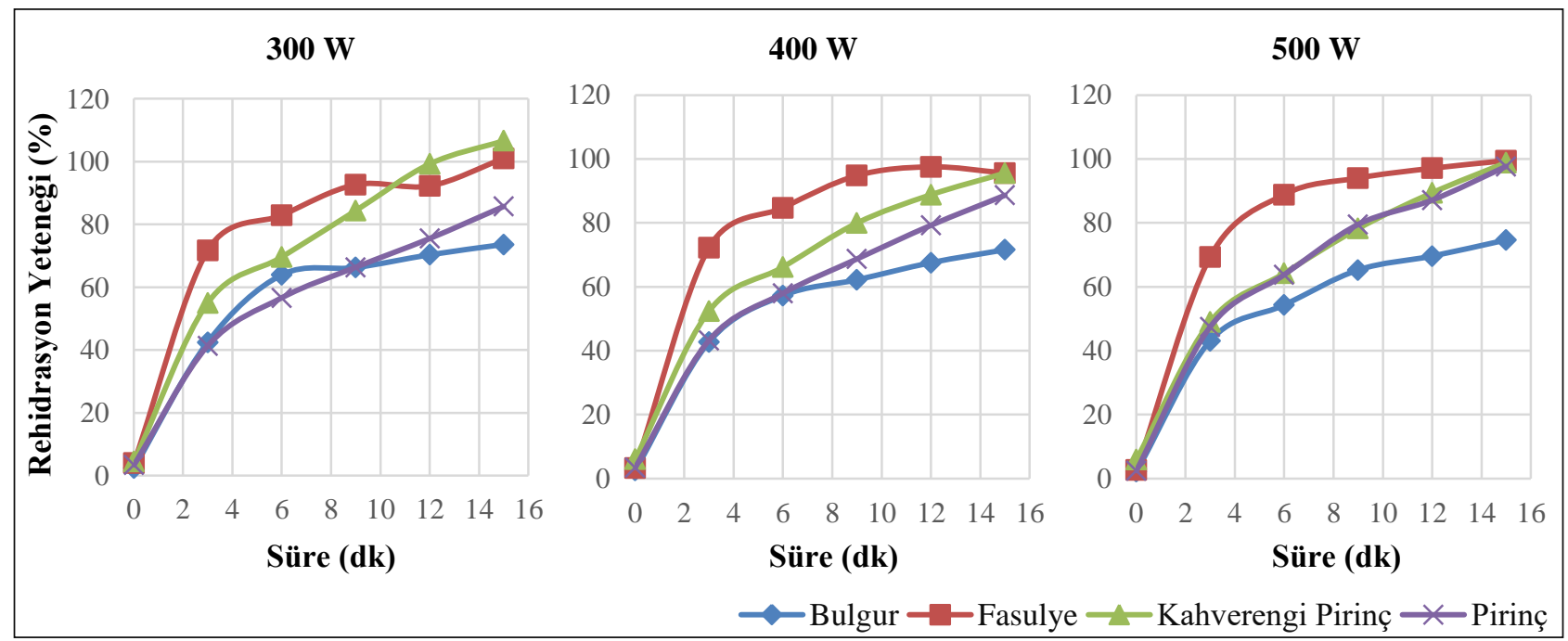

Şekil 2. Farklı IR yayıcı güçlerinde kurutulan örneklerin, sürelere karşı rehidrasyon yetenekleri

İnstant ürünlerin rehidrasyon sonrası tekstür sonuçları ve tekstür analizinin gerçekleştirildiği süredeki rehidrasyon yetenekleri Tablo $\underline{3}$ 'de sunulmuştur. Tekstür analizinde kullanılan rehidrasyon süresi (9. dk), materyal metot kısmında da değinildiği üzere, yapılan ön denemeler neticesinde belirlenmiştir. Yapılan tekstür profil analizi sonucunda pirinç örneklerinin işlem parametrelerinden istatistiksel olarak etkilenmediği görülmüştür ( $p>0.05)$. Bununla beraber yapışkanlık ve elastikiyet özellikleri IR yayıcı gücüne göre bir fark oluşturmamıştır ( $p>0.05$ ). Esneklik özelliği için yalnızca bulgur örneklerinde, bağlılık özelliği için ise yalnızca fasulye örneklerinde IR yayıcı gücünün etkisi anlamlı bir fark yaratmıştır ( $p<0.05)$. 


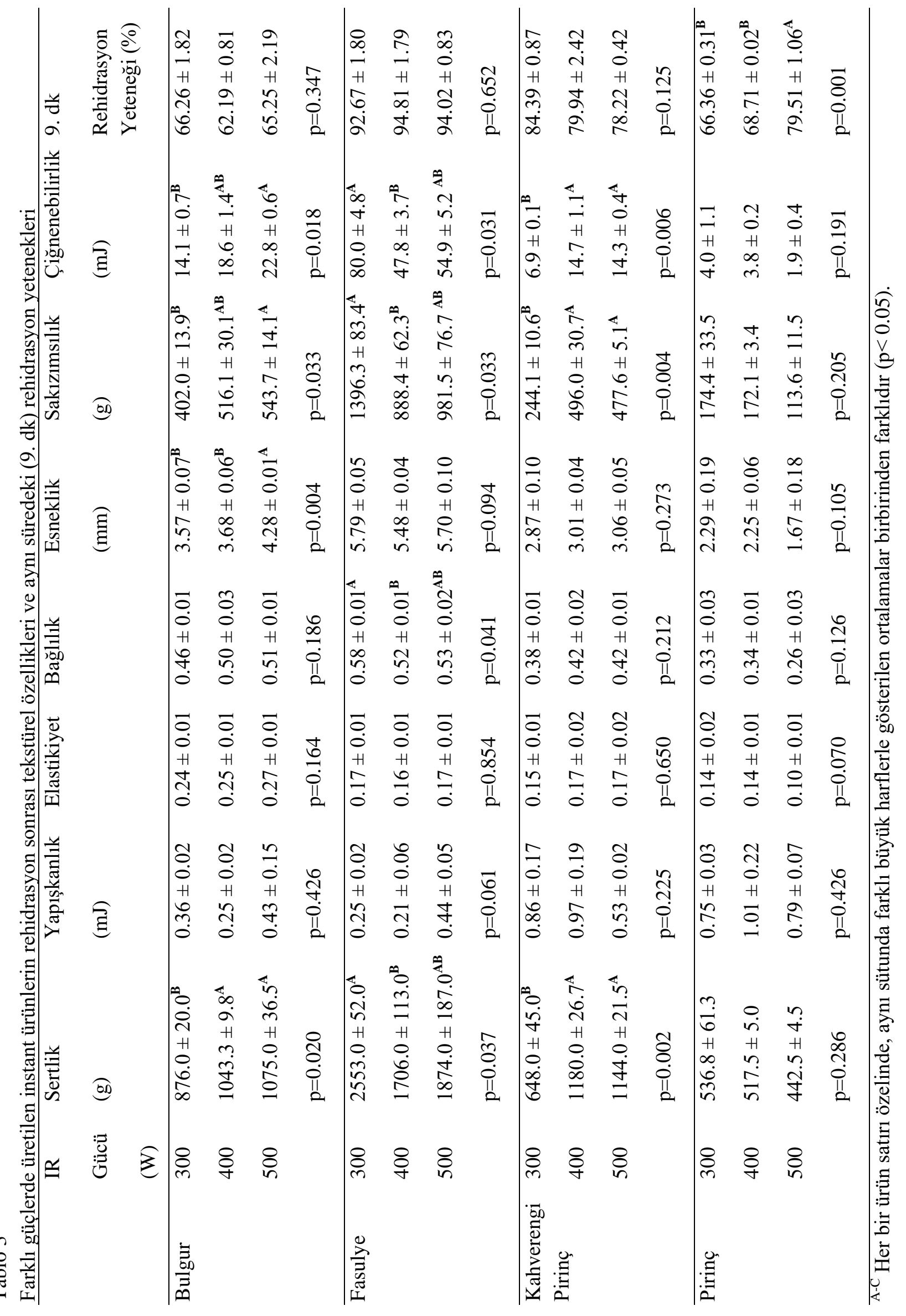


Bulgur örneklerinde farklı IR yayıcı güçleri için sertlik, esneklik, sakızımsılık ve çiğnenebilirlik özellikleri arasında istatistiksel olarak önemli farklılıklar görülmüştür $(p<0.05)$. Bununla beraber IR enerjiye maruz kalma süresi arttıkça (veya IR yayıcı gücü azaldıkça) bu özelliklerin azalma eğiliminde olduğu belirlenmiştir.

Fasulye örneklerinde ise en yüksek sertlik, bağl1lık, sakızımsılık ve çiğnenebilirlik özelliklerinin değerleri 300 W IR yayıcı gücünde görülmüştür $(\mathrm{p}<0.05)$. Kurutmanın yapıldığı $300 \mathrm{~W}$ IR yayıcı gücünde kahverengi pirinç örneklerinde ise sertlik, sakızımsılık ve çiğnenebilirlik özellikleri, 400 ve $500 \mathrm{~W}$ değerlere göre istatistiksel olarak farklı ve önemli derecede düşük olduğu belirlenmiştir $(p<0.05)$. Ayrıca tüm örneklerde sertlik değerlerinin yüksek olduğu koşullarda, çiğnenebilirlik değerlerinin de yüksek olduğu görülmüştür. Bulgulara uyumlu olarak, Park, Kim ve Kim (2001), enstrümantal tekstür analizlerinde çiğnenebilirlik ve sertlik arasında önemli derecede bir ilişki olduğunu bildirmişlerdir.

Kepek tabakasına sahip kahverengi pirinçlerin düşük IR gücü ve uzun kuruma süresi ile rehidrasyon yeteneklerinin iyileştiği ve sertlik değerlerinin azaldığı; aksine kepek tabakasına sahip olmayan pirinç örneklerinin aynı eğilimi, yüksek IR gücü ve kısa kuruma süresi ile sergilediği görülmüştür (Tablo $\underline{3}$ ).

Yapılan çalışmalarda IR enerjiye maruz kalma sürelerinin artmasıyla tanelerde iç stresin artması sonucu endosperm çatlaklarının oluşumunun teşvik edildiği rapor edilmiştir (Timm vd., 2020; Wu, Zhang ve Li, 2017). Bununla birlikte kahverengi pirinç örneklerinde IR yayıcı gücü ile rehidrasyon yeteneği ortalamaları arasında negatif bir ilişkinin olduğu tespit edilmiştir. Bu durumda, IR enerjiye maruz kalma süresinin artmasıyla kahverengi pirincin sahip olduğu kepek tabakası ile beraber endosperm çatlaklarının artması, sıcak suyun taneye daha kolay nüfuz etmesini sağlamış olabilir (Timm vd., 2020). Böylelikle tanenin rehidrasyon yeteneğinin artması ile daha yumuşak bir yapı sergilediği düşünülebilir. Nitekim, tüm örneklerde en düşük sertlik değerleri karşıllğında yüksek rehidrasyon yetenekleri görülmüştür (Tablo $\underline{3}$ ). Ayrıca kahverengi pirincin kepek tabakasının doğası gereği su bağlama yeteneğinin olması, pirinç örneklerine kıyasla bu durumu ayrıca teşvik etmiş olabilir (Malekian vd., 2000).

Pirinç örneklerinde ise IR yayıcı gücünün yüksek olduğu durumda sertlik değerinin nispeten azaldığı ve rehidrasyon yeteneğinin önemli ölçüde arttığı $(\mathrm{p}<0.05)$ saptanmıştır. Bu durumun, hızlı kuruma ile birlikte tane yapısındaki büzülmelerin minimum düzeyde olmasıyla gözenekli yapı oluşturmasının bir sonucu olduğu düşünülmektedir (Le ve Jittanit, 2015). Benzer şekilde Jiao vd. (2014) instant pirincin kurutulmasında hava sıcaklığı ve mikrodalga güçlerinin artmasıyla rehidrasyon hızının arttığını bildirmişlerdir. Nitekim birçok araştırmacı, uzun kuruma süreleri ile birlikte numunenin rehidrasyon kapasitesi ve mikro yapısı üzerinde olumsuzluklara neden olduğunu rapor etmişlerdir (Chen vd., 2014; Vadivambal ve Javas, 2007).

\section{Sonuçlar}

İnstant gida üretimi önce pişirme daha sonra uygun kurutma tekniği ile kurutmaya dayanan bir prosestir. Bu çalışmada geleneksel kurutmaya alternatif, orta dalga IR yayıcı güçlerinin $(300,400,500 \mathrm{~W})$ bulgur, fasulye, kahverengi ve beyaz pirinç numuneleri için incelenen özelliklerine etkisi belirlenmiştir. IR yayıc1 gücünün artmasıyla kuruma sürelerinin beklenen şekilde azaldığı ve kuruma sonrası tüm instant ürünlerin muhafaza açısından güvenli $\mathrm{a}_{\mathrm{w}}$ değerlerine (0.29-0.49) ulaştığ 1 belirlenmiştir. HMF sonuçları incelendiğinde kahverengi ve beyaz pirinçte tespit edilememiş ancak bulgur ve fasulye örneklerinde tespit edilmiştir. Bununla birlikte, bulgur ve fasulye örnekleri için HMF oluşumunda IR enerjiye maruz kalma süresinin etkin olduğu saptanmıştır. Ayrıca kurutma işleminin renk değerlerindeki değişimin pratikte önemli olmadığı sonucu ortaya çıkmıştır. İnstant gıdaların önemli bir diğer özelliği, sıcak su ilavesi ile pişmiş haline geri dönüşebilme (rehidrasyon) yetenekleridir. Nitekim yüksek rehidrasyon yetenekleri sergileyen örneklerin sertlik değerlerinde azalma eğilimi görülmüştür. Bulgur ve fasulye örnekleri için IR yayıcı gücü rehidrasyon 
yeteneklerini etkilemediğinden, HMF oluşumunu da minimuma indirmesinden dolayı hızlı kurutma (500 W) önerilmektedir. Kahverengi pirinçlerin uzun kuruma süresi ile rehidrasyon yeteneklerinin iyileştiği ve sertlik değerlerinin azaldığı; aksine beyaz pirinç örneklerinin aynı eğilimi kısa kuruma süresi ile sergilediği görülmüştür. Yavaş kurutmanın $(300 \mathrm{~W})$ kahverengi pirinç tanelerinin iç stresini arttırarak kepek tabakası ile birlikte çatlaklara neden olması; kepek tabakasına sahip olmayan pirincin hızlı kurutmayla (500 W) tane yapısının büzülmesinin minimuma inmesi ve gözeneklerin oluşmasıyla rehidrasyon yeteneklerinin iyileştiği düşünülmektedir. Ek olarak, söz konusu mekanizmaların daha iyi açıklanabilmesi adına ileriki çalışmalarda tanenin mikro yapısının incelenmesi önerilmektedir.

\section{Teşekkür}

$\mathrm{Bu}$ çalışma, henüz fikir ve prototip aşamasında iken 26-27 Nisan 2018 tarihlerinde Çanakkale'de düzenlenen "1. Proje Pazarı" etkinliğinde, alanında en iyi poster ödülüne layık görülmüş ve alınan ödül bilimsel çalışmanın hayata geçirilmesinde maddi-manevi önemli bir paya sahip olmuştur. Bu motivasyon fırsatını bizlere sunan Çanakkale Valiliği'ne, Çanakkale Onsekiz Mart Üniversitesi'ne ve "1. Proje Pazarı" etkinliğinin tüm paydaşlarına teşekkürlerimizi sunarız.

\section{Yazar Katkıları}

Barış Burak Albayrak: Veri toplamış, analizini yapmış ve makaleyi yazmıştır.

Necati Barış Tuncel: Analizi planlamış, tasarlamış ve makaleyi yazmıştır.

Habib Kocabıyık: İstatistiksel analizlerini tasarlamış, yapmış ve makaleyi yazmıştır.

\section{Çıkar Çatışması}

Yazarlar çıkar çatışması bildirmemişlerdir.

\section{Kaynaklar}

AACC, American Association of Cereal Chemists, Approved Methods, 2000. No: 44-15a, 10th edition, St. Paul, MN, USA

Basman, A. ve Yalcin, S. (2011). Quick-boiling noodle production by using infrared drying. Journal of Food Engineering, 106(3), 245-252. doi:https://doi.org/10.1016/j.jfoodeng.2011.05.019

Cemeroğlu, B., Karadeniz, F. ve Özkan, M. (2003). Meyve ve Sebze İşleme Teknolojisi. Gıda Teknolojisi Derneği Yayınları, 28, s. 541, Ankara.

Chen, X., Qian, P., Zhang, X., Liu, F. ve Lu, R. (2014). Improving instant rice quality by novel combined drying. Drying Technology, 32(12), 1448-1456. doi:https://doi.org/10.1080/07373937.2014.900503

Chua, K. J. ve Chou, S. K. (2003). Low-cost drying methods for developing countries. Trends in Food Science and Technology, 14, 519-528. doi:https://doi.org/10.1016/j.tifs.2003.07.003

Das, I. ve Das, S. K. (2010). Emitters and infrared heating system design. In: Pan, Z. ve Atungulu, G. G. (Ed.). Infrared Heating For Food And Agricultural Processing. CRC Press, USA. 57-88.

Erkmen, O. ve Bozoglu, T. F. (Ed.). (2016). Food Microbiology: Principles into Practice: Vol. 2. John Wiley $\&$ Sons, Somerset, NJ.

Güray, T., Tuncel, N. Y., Tuncel, M. ve Uysal, U. (2019). Validated micellar electrokinetic capillary chromatography (MECC) method for determination of 5-hydroxymethylfurfural in honey and comparison with HPLC. Chemical Papers, 73, 2209-2220. doi:https://doi.org/10.1007/s11696-019- 
$\underline{00770-5}$

İsmail, O. (2017). Güneş altında kurutulmuş havuç dilimlerinin rehidrasyon kinetiğinin incelenmesi. Gazi Üniversitesi Mühendislik Mimarlı Fakültesi Dergisi, 32(2), 0-0. doi:https://doi.org/10.17341/gazimmfd.322157

Jiao, A., Xu, X. ve Jin, Z. (2014). Modelling of dehydration-rehydration of instant rice in combined microwave-hot air drying. Food and Bioproducts Processing, 92(3), 259-265. doi:https://doi.org/10.1016/j.fbp.2013.08.002

Jun, S., Krishnamurthy, K., Irudayaraj, J. ve Demirci, A. (2010). Fundamentals and theory of infrared radiation. In: Pan, Z. ve Atungulu, G. G. (Ed.). Infrared Heating For Food and Agricultural Processing. CRC Press, USA. 2 p.

Kayacan, S., Karasu, S., Akman, P. K., Goktas, H., Doymaz, I. ve Sagdic, O. (2020). Effect of different drying methods on total bioactive compounds, phenolic profile, in vitro bioaccessibility of phenolic and HMF formation of persimmon. LWT - Food Science and Technology, 118, 108830. doi:https://doi.org/10.1016/j.lwt.2019.108830

Kocabiyik, H., Yilmaz, N., Tuncel, N. B., Sümer, S. K. ve Büyükcan, M. B. (2014). The effects of middle infrared radiation intensity on the quality of dried tomato products. International Journal of Food Science And Technology, 49, 703-710. doi:https://doi.org/10.1111/ijfs.12353

Krishnamurthy, K., Khurana, H. K., Jun, S., Irudayaraj, J. ve Demirci, A. (2008). Infrared heating in food processing: an overview. Comprehensive Reviews in Food Science and Food Safety, 7, 2-13. doi:https://doi.org/10.1111/j.1541-4337.2007.00024.x

Le, T. Q. ve Jittanit, W. (2015). Optimization of operating process parameters for instant brown rice production with microwave-followed by convective hot air drying. Journal of Stored Products Research, 61, 1-8. doi:https://doi.org/10.1016/j.jspr.2015.01.004

Malekian, F., Rao, R. M., Prinyawiwatkul, W., Marshall, W. E., Windhauser, M. ve Ahmedna, M. (2000). Lipase and lipoxygenase activity, functionality, and nutrient losses in rice bran during storage. LSU AgCenter, Baton Rouge, LA 70803. 870, 9-10.

Mayor, L. ve Sereno, A. M. (2004). Modelling shrinkage during convective drying of food materials: a review. Journal of Food Engineering, 61(3), 373-386. doi:https://doi.org/10.1016/S0260$\underline{8774(03) 00144-4}$

Mongpreneet, S., Abe, T. ve Tsurusaki, T. (2002). Accelerated drying of welsh onion by far infrared radiation under vacuum conditions. Journal of Food Engineering, 55, 147-156. doi:https://doi.org/10.1016/S0260-8774(02)00058-4

Nachaisin, M., Jamradloedluk, J. ve Niamnuy, C. (2016). Application of combined far-infrared radiation and air convection for drying of instant germinated brown rice. Journal of Food Process Engineering. 39(3), 306-318. doi:https://doi.org/10.1111/jfpe.12226

Nowak, D. ve Lewicki, P. P. (2004). Infrared drying of apple slices. Innovative Food Science and Emerging Technologies, 5(3), 353-360. doi:https://doi.org/10.1016/j.ifset.2004.03.003

Park, J. K., Kim, S. S. ve Kim, K. O. (2001). Effect of milling ratio on sensory properties of cooked rice and on physicochemical properties of milled and cooked rice. Cereal Chemistry, 78, 151-56. doi:https://doi.org/10.1094/CCHEM.2001.78.2.151

Ramasamy, A. K., Kalaivanan, G. ve Sukumar, S. (2005). Consumer behaviour towards instant food products. Indian Journal of Marketing, 35(6), 24-25. Erişim Adresi: 
http://www.indianjournalofmarketing.com/index.php/ijom/article/view/34210

Ramesh, M. N. ve Rao, P. N. S. (1996). Drying studies of cooked rice in a vibrofluidized bed drier. Journal of Food Engineering, 27(4), 389-396. doi:https://doi.org/10.1016/0260-8774(95)00018-6

Ratti, C. (2001). Hot air and freeze-drying of high-value foods: a review. Journal of Food Engineering, 49(4), 311-319. doi:https://doi.org/10.1016/S0260-8774(00)00228-4

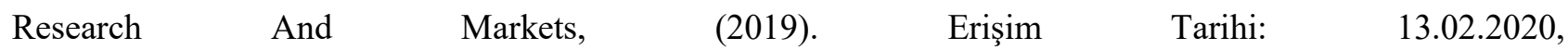
https://www.researchandmarkets.com/reports/4763082/instant-noodles-market-global-industry-trends

Rufian-Henares, A. J., Delgado-Andrade, C. ve Morales, J. F. (2009). Assessing the maillard reaction development during the toasting process of common flours employed by the cereal products industry. Food Chemistry, 114(1), 93-99. doi:https://doi.org/10.1016/j.foodchem.2008.09.021

Savas, K. ve Basman, A. (2016). Infrared drying: A promising technique for bulgur production. Journal of Cereal Science. 68, 31-37. doi:https://doi.org/10.1016/j.jcs.2015.11.001

Sripinyowanich, J. ve Noomhorm, A. (2013). Effects of freezing pretreatment, microwave-assisted vibrofluidized bed drying and drying temperature on instant rice production and quality. Journal of Food Processing and Preservation, 37, 314-324. doi:https://doi.org/10.1111/j.1745-4549.2011.00651.x

Timm, N. S., Lang, G. H., Ferreira, C. D., Pohndorf, R. S. ve de Oliveira, M. (2020). Infrared radiation drying of parboiled rice: Influence of temperature and grain bed depth in quality aspects. Journal of Food Process Engineering. 43(4), 1-12. doi:https://doi.org/10.1111/jfpe.13375

Tuncel, N. Y. ve Tuncel, N. B. (2016). Kızılötesi teknolojisi ve gıda işlemedeki kullanımı. Akademik Gıda, 14(2), 196-203. Erişim Adresi: https://dergipark.org.tr/tr/download/article-file/1186250

Vadivambal, R. ve Javas, D. S. (2007). Changes in quality of microwave-treated agricultural products-a review. Biosystems Engineering, 98(1), 1-16. doi:https://doi.org/10.1016/j.biosystemseng.2007.06.006

Wiriyaumpaiwong, S., Soponronnarit, S. ve Prachayawarakorn S. (2004). Comparative study of heating processes for full-fat soybeans. Journal of Food Engineering, 65(3), 371-382. doi:https://doi.org/10.1016/j.jfoodeng.2004.01.036

Wu, J., Zhang, H. ve Li, F. (2017). A study on drying models and internal stresses of the rice kernel during infrared drying. Drying Technology, 35(6), 680-688. doi:https://doi.org/10.1080/07373937.2016.1201834 